\title{
TEJIDO PROSTÁTICO ECTÓPICO EN VEJIGA URINARIA
}

\author{
A. SOUSA ESCANDÓN \\ Servicio de Urología. Hospital Comarcal de Monforte. Lugo. \\ Actas Urol Esp. 27 (1): 68-69, 2003
}

\section{Señor Director:}

Me gustaría felicitar a los autores de este trabajo $^{1}$ por la presentación de esta infrecuente patología de probable origen embrionario y que nos sirve de modelo para reflexionar sobre algunos aspectos de la fisiopatología de la hiperplasia benigna prostática. Aunque se ha especulado que el probable origen de este tejido anómalo sea la metaplasia del epitelio transicional, la mayoría de autores concuerda en que su origen es secundario a la persistencia o migración de vestigios embrionarios hacia la vejiga urinaria ${ }^{2}$. Sin embargo, a la luz de los estudios actuales parece más probable que sea debido a una combinación de ambos factores; es decir, la metaplasia del tejidourotelial adulto secundaria a una reprogramación inducida por un resto embrionario mesenquimal subyacente.

Las interacciones entre el mesénquima y el epitelio son esenciales para el desarrollo del tracto reproductivo masculino. La implantación de tejido del mesénquima embrionario fetal del Seno Urogenital (MSUG) bajo tejido epitelial del seno urogenital (ESUG) produce la “inducción” del desarrollo de un tejido prostático maduro, este proceso remeda al que se produce normalmente durante la embriogénesis prostática ${ }^{3}$. Sin embargo, experimentalmente se ha comprobado que si se implanta tejido del mesénquima embrionario fetal del Seno Urogenital (MSUG) bajo el urotelio de una vejiga urinaria adulta, se produce una "inducción instructiva" del epitelio, el cual se transforma en un tejido prostático plenamente desarrollado mediante la reprogramación de sus características morfológicas y funcionales ${ }^{4}$. Este proceso sería el teórico responsable de la aparición de tejido pros- tático funcionante en el epitelio uretral o vesical del adulto; sin embargo, sólo se produciría si durante el periodo fetal se produce una migración de vestigios embrionarios del MSGU fuera de la uretra prostática.

Este proceso patológico podría ser útil para entender cómo y porqué se produce la hiperplasia benigna prostática. Se sabe que la implantación de tejido prostático hiperplásico humano en el lóbulo ventral de la próstata no induce el crecimiento del mismo, mientras que si se implanta MSGU se produce una potente estimulación de su crecimiento $^{5}$. Según la hipótesis del "redespertar" embrionario de Mc Neal ${ }^{6}$, para que se produzca el crecimiento prostático del adulto es necesario que se estimulen las células mesenquimales periprostáticas que derivan del MSGU, lo cual induciría al epitelio suprayacente a reiniciar su desarrollo embrionario mediante aparición y crecimiento de nuevas ramificaciones glandulares, además de aumentar la secreción de proteínas próstato-específicas ${ }^{7}$.

Conocemos también que la estimulación del MSGU mediante la testosterona produce un incremento en la formación de nuevos ductos prostáticos, proceso que ocurre paralelamente con el incremento de la proteína Sonic Hedgehog ${ }^{8}$. Esta asociación se comprueba añadiendo anticuerpos contra dicha proteína mensajera en el medio de cultivo donde se realiza el experimento y apreciando como se frena el crecimiento y la morfogénesis ductal prostática ${ }^{8}$. Mientras los receptores androgénicos del mesénquima son imprescindibles para iniciar el desarrollo prostático del adulto, se sabe que si implantamos MSGU normal bajo ESGU de rata andrógeno insensible se produce un 
desarrollo subtotal del tejido prostático, indicando que la estimulación de los receptores androgénicos del epitelio también son importantes en los estados finales de la morfogénesis y el inicio de la función secretora prostática ${ }^{9}$.

La única pieza del puzzle que nos falta por conocer es qué factor o factores estimulan el redespertar del estroma prostático derivado del MSGU? ${ }^{7}$. El mejor candidato para ocupar esa plaza sería un estímulo hormonal androgénico puro o más probablemente un disbalance entre estrógenos y andrógenos. Sin embargo, este no puede ser el único factor ya que se sabe que el MSGU puede inducir un sobrecrecimiento prostático en ausencia completa de esteriodes exógenos, lo que hace barajar la presencia de "artistas secundarios" como distintos factores de crecimiento o la prolactina. El mayor conocimiento de estos mecanismos nos dará en el futuro con la respuesta al tratamiento, o mejor aún la prevención, de la hiperplasia benigna prostática.

\section{REFERENCIAS}

1. SÁNCHEZ JM, FERNÁNDEZ A, GÓMEZ SC, PARRA L, GARCÍA J.: Tejido prostático ectópico en vejiga urinaria. Actas Urol Esp 2002; 26 (5): 369-371.

2. RICHTER S, SAGHI N, NISSENKORN I: Supratrigonal ectopic prostate: case report and review of the literature. Urol Int 1991; 46 (1): 96-98.
3. CHUNG LW, CUNHA GR.: Stromal-epithelial interactions: II. Regulation of prostatic growth by embrionic urogenital sinus mesenchyme. Prostate 1983; 4 (5): 503-511.

4. DOJANCOUR AA, CUNHA GR.: Induction of prostatic morphology and secretion in urothelium by seminal vesicle mesenchyme. Development 1995; 112187: 2.199-2.207.

5. JAROW JP, ISAACS JT: Prostatic growth effects of rat urogenital sinus and human prostatic tissue in the rat. Prostate 1989; 14 (4): 301-308.

6. MC NEAL.: Origin and evolution of benign prostatic enlargement. Invest Urol 1978; 15 (4): 340-345.

7. CHUNG LW, MATSUURA J, ROCCO AK, THOMPSON TC, MILLER GJ, RUNNER MN: A new mouse model for prostatic hyperplasia: induction of adult prostatic overgrowth by fetal urogenital sinus implants. Prog Clin Biol Res 1984; 145: 291-306.

8. PODLASEK CA, BARNETT DH, CLEMENS JQ, BAK PM, BUSHMAN W.: Prostate development requires Sonic hedgehog expressed by the urogenital sinus epithelium. Dev Biol 1999; 209 (1): 28-39.

9. DOJANCOUR AA, CUNHA GR.: Assessment of prostatic protein secretion in tissue recombinants made of urogenital sinus mesenchyme and urothelium from normal or androgen-insensitive mice. Endocrinology 1993; 132 (6): 2.342-2.350.

Dr. A. Sousa Escandón

Servicio de Urología

Hospital Comarcal de Monforte

Corredoira, s/n

27400 Monforte de Lemos (Lugo)

(Trabajo recibido el 16 de julio 2002) 